\title{
A Rapid Seedling Resistance Assay Identifies Wild Tomato Lines That Are Resistant to Pseudomonas syringae pv. tomato Race 1
}

\author{
J. A. Hassan, ${ }^{1}$ Y. J. Zhou, ${ }^{1}$ and J. D. Lewis ${ }^{1,2,+}$ \\ ${ }^{1}$ Department of Plant and Microbial Biology, University of California Berkeley, Berkeley, CA, U.S.A.; and ${ }^{2}$ Plant Gene \\ Expression Center, United States Department of Agriculture, 800 Buchanan St., Albany, CA, 94710, U.S.A.
}

Accepted 16 May 2017.

\begin{abstract}
Bacterial speck caused by Pseudomonas syringae has historically been controlled by the Pto/Prf gene cluster. Emerging strains like $P$. syringae pv. tomato race 1 overcome resistance conferred by $P t o / P r f$, and can cause serious crop loss under appropriate environmental conditions. We developed a rapid assay to screen wild tomato seedlings for resistance to $P$. syringae pv. tomato race 1. We established the seedling resistance assay using the wellcharacterized $P$. syringae pv. tomato race 0 strain, DC3000, which is recognized in tomato cultivars carrying Pto/Prf (PtoR) and causes disease in isogenic lines lacking this cluster (PtoS). We optimized infectious conditions for $P$. syringae on tomato seedlings and demonstrated that tomato seedlings respond like adult tomato plants in critical measures of susceptibility and immunity, including the hypersensitive response, rapid ion leakage, restricted bacterial proliferation, and phenotypic resistance. After establishing infectious conditions for $P$. syringae pv. tomato race 1 on tomato seedlings, we screened 96 wild accessions and identified two accessions with strong $P$. syringae pv. tomato race 1 resistance, Solanum neorickii LA1329 and $S$. habrochaites LA1253, which are also resistant to bacterial infection as adult plants. This rapid high throughput seedling assay has many advantages, including reduced plant growth time and large sample sizes, and will allow for large-scale screening of resistance in tomato.
\end{abstract}

Pseudomonas syringae is a gram-negative plant pathogenic bacterium that can infect a wide range of plant hosts and cause serious disease under appropriate environmental conditions. The bacteria typically enter the host plant through the stomata and multiply in the apoplast (Underwood et al. 2007). As a first line of defense, plants use pattern-recognition receptors (PRR) to perceive pathogen-associated molecular patterns (PAMPs) during PRR-triggered immunity (PTI) (Mott et al. 2014; Segonzac and Zipfel 2011). PTI results in mitogen-activated protein kinase cascades, reactive oxygen species production, pathogenesisrelated gene induction, callose deposition that reinforces the cell wall, and stomatal closure. The bacterium overcomes PTI, using its

${ }^{\dagger}$ Corresponding author: J. D. Lewis; E-mail: jdlewis@ berkeley.edu; Telephone: +1.510 .559 .5909 ; Fax: +1.510 .559 .5678 .

*The $e$-Xtra logo stands for "electronic extra" and indicates that three supplementary figures and one supplementary table are published online.

This article is in the public domain and not copyrightable. It may be freely reprinted with customary crediting of the source. The American Phytopathological Society, 2017. type III secretion system to deliver type III secreted effector proteins (T3SEs) across the cell wall directly into the cytoplasm of the host cell (Galán and Wolf-Watz 2006). These effector proteins can suppress PTI, which results in disease. In turn, plants evolved resistance $(R)$ genes that encode nucleotide-binding site and leucine-rich repeat (NB-LRR) proteins (Dangl and Jones 2001; Jones and Dangl 2006). NB-LRR proteins recognize specific effectors and initiate effector-triggered immunity, which is often associated with the hypersensitive response (HR), a form of localized cell death at the site of pathogen infection (Heath 2000).

Bacterial speck of tomato is a persistent agricultural problem caused by Pseudomonas syringae pv. tomato, particularly under cool, moist conditions (Pedley and Martin 2003; Schneider and Grogan 1977). Bacterial speck results in significant crop and economic losses worldwide. In the 1930s, plant breeders developed tomato lines that exhibited resistance to $P$. syringae pv. tomato race 0 strains like DC3000 (Pedley and Martin 2003). The introgression of the Pto/Prf gene cluster from Solanum pimpinellifolium into many tomato cultivars assisted in managing bacterial speck for decades (Pedley and Martin 2003; Pitblado and MacNeill 1983). The mechanism of Pto/Prfmediated resistance against $P$. syringae pv. tomato race 0 has been extensively studied. Race 0 carries two unrelated T3SEs, AvrPto and AvrPtoB, that are recognized by Pto, a serine threonine protein kinase, and Prf, a NB-LRR protein (Martin et al. 1993; Ronald et al. 1992; Salmeron et al. 1994, 1996; Scofield et al. 1996). AvrPto and AvrPtoB homologs are found in many different pathovars that infect tomato (Lin and Martin 2007). $P$. syringae pv. tomato race 0 strains that are deleted for AvrPto and AvrPtoB do not trigger Pto/Prf resistance and have highly reduced virulence in susceptible hosts (Lin and Martin 2005; Lin et al. 2006).

Worldwide surveys of $P$. syringae isolates have highlighted the prevalence of $P$. syringae pv. tomato race 1 strains (Cai et al. 2011; Kunkeaw et al. 2010). Race 1 strains are not recognized by the Pto/Prf gene cluster, as AvrPto is not present or has single nucleotide polymorphisms that prevent its recognition and the AvrPtoB protein accumulates minimally, probably because of posttranslational regulation (Kunkeaw et al. 2010; Lin et al. 2006). In addition, $P$. syringae pv. tomato race 1 strains carry unique T3SEs compared with DC3000, a $P$. syringae pv. tomato race 0 strain (Almeida et al. 2009). Race 1 outbreaks in North America and worldwide (Arredondo and Davis 2000; Buonaurio et al. 1996; Cai et al. 2011; Kunkeaw et al. 2010; Lawton and MacNeill 1986; Milijasevic et al. 2009) have expanded efforts to identify sources of resistance. Wild tomato species are known to be important reservoirs of $P$. syringae $\mathrm{pv}$. 
tomato race 1 resistance (Rose et al. 2005). Four quantitative trait loci (QTL) that control resistance to $P$. syringae pv. tomato race 1 strain A9 in $S$. habrochaites accession LA1777 were identified (Thapa et al. 2015) and a candidate resistance gene interval in S. habrochaites accession LA2109 was identified, using a mapping-by-sequencing approach (Bao et al. 2015).

To facilitate the identification of other sources of resistance, we developed a high-throughput tomato- $P$. syringae resistance assay. In proof-of-principle experiments, we demonstrate that disease and resistance responses to $P$. syringae pv. tomato race 0 (DC3000 strain) can be recapitulated in tomato seedlings that differ in the presence or absence of the Pto/Prf gene cluster. We established infectious conditions for $P$. syringae pv. tomato race 1 (T1 strain) in this assay and screened 96 wild accessions for resistance. The screen provides rigorous phenotypes of resistance or disease and allows large numbers of tomato seedlings to be screened, which is particularly important in genetically complex wild species. We identify two wild accessions with sources of resistance to $P$. syringae pv. tomato race 1 , demonstrating that the seedling resistance assay is a rapid high-throughput screen that identifies resistant tomato accessions.

\section{RESULTS}

\section{Establishing a high-throughput}

tomato- $P$. syringae resistance assay.

Screens for disease resistance in tomato typically use fourto five-week-old adult tomato plants and are, therefore, limited by the growth time, the size of plants, and the space they require for growth (Bao et al. 2015; Thapa et al. 2015). We decided to establish a high-throughput screen for resistance using tomato seedlings. This strategy has several advantages: rapid growth and turnover of plants, highly reduced needs for growth chamber space, increased numbers of individuals that can be tested, and much higher throughput. In order to establish the approach, we used the wellcharacterized pathosystem of $P$. syringae pv. tomato race 0 strain DC3000 (hereafter DC3000) that is recognized by tomato cultivars (i.e., Moneymaker [MM] or Rio Grande [RG]) carrying the Pto/Prf gene cluster (PtoR, resistant) or isogenic lines lacking this cluster (PtoS, susceptible). We decided to flood tomato seedlings, as this infection strategy could easily be performed in plate assays and it mimics the natural infection process of bacteria from leaf surfaces. We first optimized DC3000 infectivity in the tomato seedling plate assay by testing a range of bacterial and surfactant (Silwet L-77, hereafter Silwet) concentrations and through a qualitative assessment of susceptibility or resistance of MMPtoS or MM-PtoR tomato seedlings to DC3000. We evaluated various concentrations of Silwet for possible damage to cotyledons, as this could potentially obscure our ability to correctly phenotype seedlings for disease. We flooded RG-PtoR seedlings with $10 \mathrm{mM} \mathrm{MgCl}_{2}$ containing 0.01 , $0.015,0.02$, or $0.03 \%$ Silwet (Fig. 1A). At the highest Silwet concentration $(0.03 \%)$, the cotyledons were visibly damaged (Fig. 1A) and we occasionally observed damage at $0.02 \%$ Silwet (Fig. 1A and data not shown). Seedlings appeared healthy at Silwet concentrations of 0.01 and $0.015 \%$. We determined that $0.015 \%$ Silwet provided the most effective infectivity for DC3000 (data not shown).

We then tested MM-PtoS and MM-PtoR seedlings with different concentrations of DC3000 and assessed for viability at least 7 days after flooding. MM-PtoS seedlings died at all DC3000 concentrations tested (Fig. 1B). However, we observed inconsistent death at the lowest optical density of 0.001 , because some individual seedlings survived in repeated experiments (Fig. 1B). Higher optical densities of DC3000 (0.0075 and 0.01) also killed MM-PtoR seedlings, presumably because the high bacterial load overwhelmed resistance. All MMPtoR seedlings survived when flooded at an optical density of 0.005 (Fig. 1B). Taken together, our phenotypic assays suggested that an optical density of 0.005 and Silwet concentration of $0.015 \%$ provided optimal infection for tomato seedlings.

To quantitatively confirm our phenotypic observations, we carried out bacterial growth assays on individual tomato seedlings, using the same bacterial optical densities. For these assays, the seedlings were too small to core as it is typically done for Arabidopsis thaliana growth assays (Katagiri et al. 2002). Thus, we weighed the entire seedling, including the root, and normalized bacterial growth to $0.1 \mathrm{~g}$ of the seedling weight (Table 1). MM-PtoS seedlings supported high levels of bacterial growth (over $\log 8$ ) at all optical densities, while MM-PtoR seedlings supported 1 to 2 logs less growth (approximately log 7) (Fig. 1C). DC3000 bacterial growth was significantly less in MM-PtoR seedlings compared with MM-PtoS seedlings across all optical densities. These observations support the idea that the resistance observed in the seedling flood assay is due to reduced bacterial growth and is not due to a lack of entry and establishment. This quantitative data confirmed our phenotypic observations of resistance and susceptibility in tomato seedlings.

To determine if we could visualize the HR, we also carried out vacuum infiltration of DC3000 in MM-PtoR or MM-PtoS seedlings. We observed a macroscopic HR in MM-PtoR seedlings at 8 to $10 \mathrm{~h}$ postinfection, while MM-PtoS seedlings looked healthy and green and were indistinguishable from control seedlings that were infiltrated with $10 \mathrm{mM} \mathrm{MgCl}_{2}$ (Fig. 2A). To quantitatively confirm the HR, we monitored the leakage of ions into the medium and the resulting changes in conductivity over time. MM-PtoR cotyledons exhibited a very rapid loss of ions detectable at $2 \mathrm{~h}$ post-vacuum infection, as compared with MM-PtoS. DC3000 caused significantly higher ion leakage at 6 and $8 \mathrm{~h}$ postinfection in MM-PtoR compared with MM-PtoS, indicative of a HR (Fig. 2B). This is consistent with the HR and ion leakage observed in adult PtoR tomato during DC3000 infection, and a lack of these immune responses in adult PtoS plants (Laterrot 1993; Kim et al. 2002; Pedley and Martin 2003; Rosebrock et al. 2007). Thus tomato seedlings respond as adult tomato plants do in critical measures of susceptibility and immunity.

\section{Establishing infectious conditions}

\section{for $P$. syringae pv. tomato $\mathrm{T} 1$ on tomato.}

Having established a rigorous seedling resistance assay, we then began testing $P$. syringae pv. tomato race 1 strain T1 (hereafter T1) on tomato seedlings to determine the appropriate level of bacterial inoculum. Since there are no isogenic lines of tomato that differ in resistance and susceptibility, we tested RGPtoR seedlings that are susceptible to T1. All RG-PtoR seedlings exhibited symptoms of bacterial speck (chlorosis and necrotic spots) and died at optical densities of 0.0075 and higher (Fig. 3A). However, lower optical densities of 0.001 to 0.005 yielded inconsistent phenotypes in repeated experiments (Fig. 3A). Based on these observations, the optimal conditions for the seedling flood assay with $\mathrm{T} 1$ were an optical density of 0.0075 and $0.015 \%$ Silwet. To confirm that MM-PtoS, MM-PtoR, RG-PtoS, and RG-PtoR cultivars were all susceptible to $\mathrm{T} 1$, we carried out dip inoculations on adult plants. These cultivars showed similarly severe disease symptoms, indicating that they cannot recognize T1 (Supplementary Fig. S1). 
Screening wild tomato seedlings for resistance to $\mathbf{T} 1$.

Wild tomato species are important reservoirs of genetic diversity and their genetic composition reflects adaptation to various environments, habitats, and pathogens. Therefore, screens for genetic resistance to pathogens, in particular $P$. syringae pv. tomato race1, have relied upon wild tomato germplasm (Bao et al. 2015; Rose et al. 2005; Thapa et al. 2015). We screened 96 wild tomato accessions in the seedling assay for resistance to T1 (Supplementary Table S1). For 85 wild accessions, all seedlings were susceptible in the primary screen and showed the following disease symptoms: cotyledons were dropped, shriveled, chlorotic or had speck, the shoot hypocotyl and apical meristem were brown, and there was no new growth. For the remaining 11 accessions, at least one seedling survived and displayed a range of phenotypes (Table 2; Fig. 3B andC). Some surviving seedlings had green cotyledons with very little browning of the hypocotyl, while others dropped their cotyledons and showed some browning of the hypocotyl, mild chlorosis, and specks. However, all surviving seedlings consistently displayed a healthy shoot apical meristem and new green vegetative growth. We propagated individual resistant seedlings and retested their progeny in a secondary screen, to test for reproducibility, heritability, and resistance frequency (Table 2). Using our phenotypic assay, we confirmed that 10 of 11 wild accessions displayed resistance to T1 (Table 2; Fig. 3B and C). To ensure that resistant seedlings did not simply have delayed disease symptoms, we transplanted seedlings 10 days after the flood infection from Murashige and Skoog (MS) plates onto soil (Table 2). Surviving seedlings grew into healthy adult plants (Fig. $3 \mathrm{D}$ and E; Table 2).

\section{S. neorickii LA1329 and S. habrochaites LA1253 display resistance to $T 1$.}

Our secondary screen identified S. neorickii LA1329 and S. habrochaites LA1253 as the strongest wild accession candidate lines (Fig. 3B and C). LA1329 displayed 63\% seedling
A

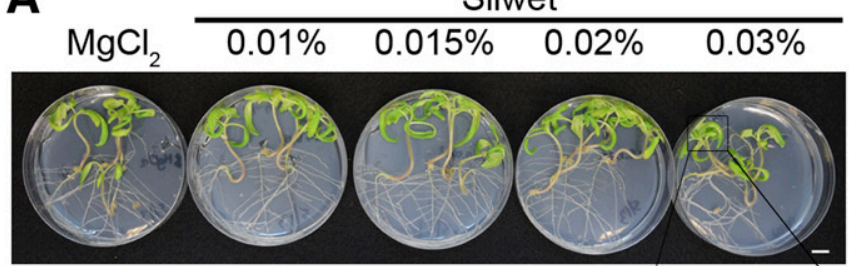

Rio Grande-PtoR

B
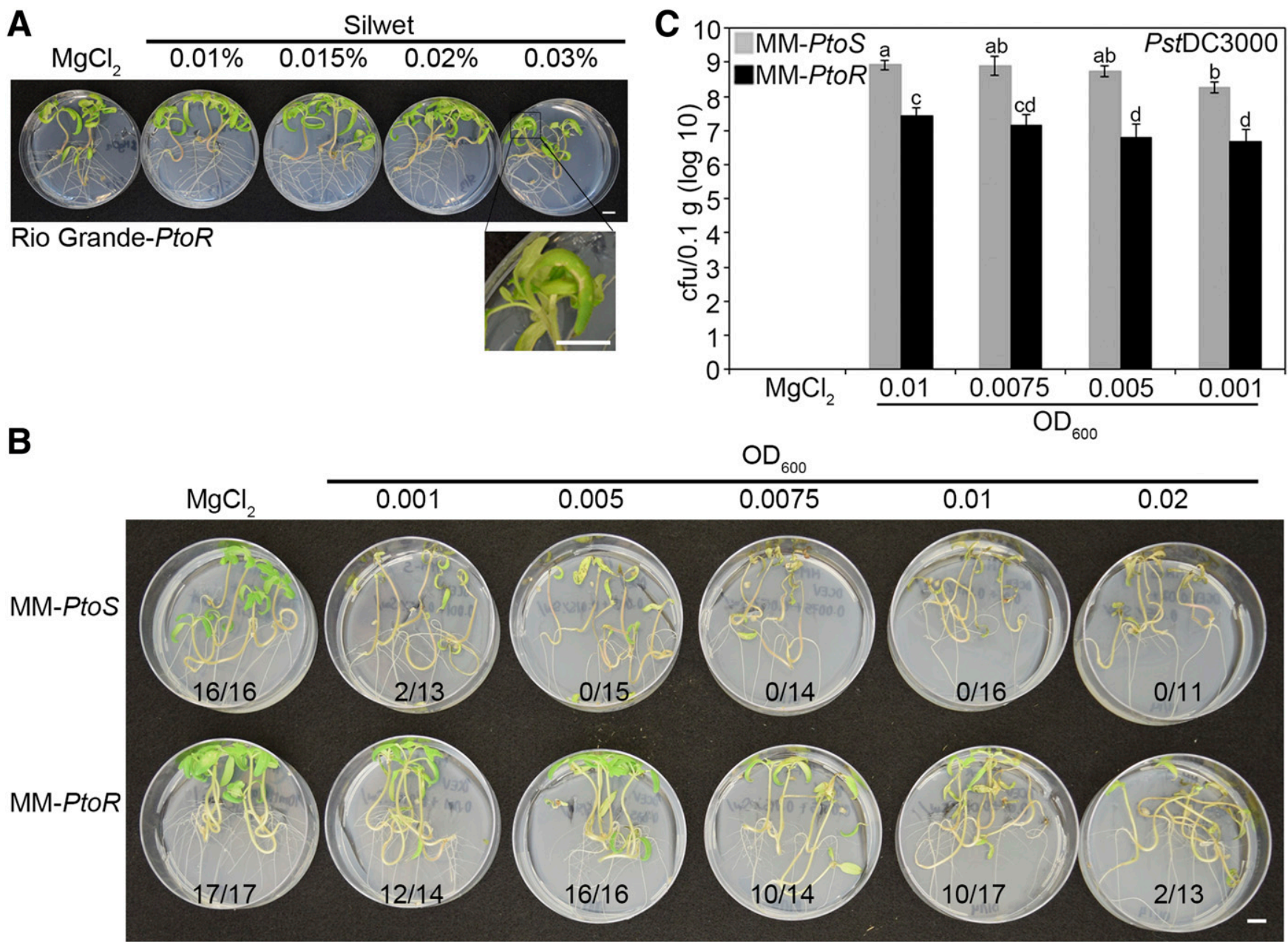

Fig. 1. Optimization of Silwet concentrations and Pseudomonas syringae pv. tomato DC3000 optical densities in tomato seedlings. A, High Silwet concentrations cause damage to tomato cotyledons. Tomato seedlings were grown on $0.5 \times$ Murashige and Skoog (MS) plates for 10 days, before being flooded with $10 \mathrm{mM} \mathrm{MgCl}$ containing the indicated concentrations of Silwet. Plants were phenotyped 7 days after flooding. The scale bar is $1 \mathrm{~cm}$. B, Phenotypic characterization of resistance or disease symptoms 7 days postinfection. Moneymaker-PtoS (MM-PtoS) or Moneymaker-PtoR (MM-PtoR) tomato seedlings were grown on $0.5 \times \mathrm{MS}$ plates for 10 days, before being flooded with $10 \mathrm{mM} \mathrm{MgCl}{ }_{2}$ containing the indicated optical densities of $P$. syringae pv. tomato DC3000 (PstDC3000) and 0.015\% Silwet. MM-PtoS seedlings are susceptible at all indicated optical densities. MM-PtoR seedlings are resistant at optical densities of 0.001 to 0.005 , but resistance is overwhelmed at very high optical densities $(0.01$ to 0.02$)$. The numbers under each plate indicate the number of seedlings that survived out of the total number tested. The scale bar is $1 \mathrm{~cm}$. C, Quantitative optimization of DC3000 optical densities in resistant and susceptible tomato seedlings. MM-PtoS or MM-PtoR tomato seedlings were grown and were flooded as described in B. Bacterial counts were determined 4 days postinfection on four to five seedlings at each optical density and were normalized to $0.1 \mathrm{~g}$ of tissue. Differences between means were determined by a one-factor analysis of variance, using a general linear model procedure $(P<0.001)$ followed by multiple comparisons of means, using Tukey's post hoc test. Different letters indicate significant differences among treatments. The error bars indicate the standard deviation. The experiment was repeated three times with similar results. 
survival $(n=38)$ and LA1253 displayed 68\% seedling survival $(n=41)$. Seven $S$. pimipinellifolium lines and one $S$. neorickii line were classified as weaker candidates (Table 2), because only 5 to $35 \%$ of seedlings were resistant. We carried out bacterial growth assays on flooded LA1329 seedlings to quantitatively confirm our phenotypic observations and ensure that the seedlings were infected. In order to both measure bacterial growth and evaluate the phenotypes on individual seedlings, we carried out growth assays on one cotyledon from each seedling and incubated the seedling at $22^{\circ} \mathrm{C}$ for at least 10 days, to correlate seedling survival or resistance with the level of bacterial growth. MM-PtoS seedlings displayed consistent reproducible disease symptoms including chlorosis, speck, and necrosis, in these assays. We found that LA1329 seedling phenotypes could be separated into two groups: susceptible seedlings exhibited symptoms of disease (chlorosis, speck, necrosis, and death), while resistant seedlings displayed healthy shoot apical meristems and new green vegetative growth and survived. The growth assay data for each specific seedling was similarly binned, based on the phenotypic observations of that seedling. Out of 45 tested LA1329 seedlings, 18 were susceptible and supported high bacterial growth while 27 were resistant and supported lower bacterial growth (Fig. 4A). We observed a $1 \log$ reduction in bacterial growth in phenotypically resistant LA1329 seedlings (log 6.7) compared with phenotypically susceptible LA1329 seedlings (log 7.7) and the control MM-PtoS seedlings (log 7.7) (Fig. 4B). This result confirms that LA1329 displays resistance to T1 and supports significantly less bacterial growth.

We also carried out growth assays and phenotypic evaluation of LA1253 seedlings to confirm the results of our secondary screen. Out of 35 tested LA1253 seedlings, 15 were susceptible and 20 were resistant. We found that LA1253 seedlings also could be separated into two groups, as observed for LA1329 (Supplementary Fig. S2). We observed a $1 \log$ reduction in bacterial growth in phenotypically resistant LA1253 seedlings ( $\log 6.5)$ compared with phenotypically susceptible LA1253 seedlings (log 7.6) and the control MM-PtoS seedlings $(\log 7.6)$.

\section{Resistance to $\mathrm{T} 1$ is maintained}

in adult LA1329 and LA1253 tomato.

Disease resistance can be developmentally regulated and can be specific to the developmental stage of the plant (DeveleyRivière and Galiana 2007; Whalen 2005). In order to assess whether the resistance identified in LA1329 tomato seedlings extends to adult plants, we conducted dip inoculations with T1 of plants grown to the four- to six-leaf stage. After incubating the plants under high humidity conditions for one week, LA1329 plants were asymptomatic or exhibited very mild disease symptoms compared with control MM-PtoS plants (Fig. 5A). We quantitatively measured bacterial growth in LA1329 plants and found further support for these phenotypic observations, as there was a significant $1 \log$ reduction in bacterial growth in LA1329 (log 5) compared with the susceptible MMPtoS plants $(\log 6)$ (Fig. 5B).

Table 1. Average mass of Moneymaker seedlings

\begin{tabular}{lcc}
\hline Line & $\begin{array}{c}\text { Number of } \\
\text { individuals }\end{array}$ & $\begin{array}{c}\text { Average weight } \pm \\
\mathbf{S D}^{\mathbf{z}}(\mathbf{g})\end{array}$ \\
\hline MM-PtoS & 15 & $0.091 \pm 0.035 \mathrm{~g}$ \\
MM-PtoR & 14 & $0.117 \pm 0.056 \mathrm{~g}$ \\
Combined MM-PtoS and & 29 & $0.100 \pm 0.047 \mathrm{~g}$ \\
MM-PtoR & & \\
\hline
\end{tabular}

${ }^{\mathrm{z}} \mathrm{SD}=$ standard deviation.
We also conducted dip inoculations of LA1253 plants at the four- to six-leaf stage. We quantitatively measured bacterial growth in LA1253 plants and found there was a significant 1.5 $\log$ reduction in bacterial growth in LA1253 (log 4.3) compared with the susceptible RG-PtoR plants (log 5.8) (Supplementary Fig. S3). Bao and colleagues (2015) independently identified LA1253 in their screen of adult tomato plants with resistance to $\mathrm{T} 1$. These results, taken together, suggest that resistance to T1 is not developmentally specific to the seedling stage in these lines.

\section{DISCUSSION}

Disease screens on adult crop plants are limited by the size of the plants, the amount of space they require, physical constraints of growth chambers, and long growth times. We sought to establish a rigorous seedling-based assay for resistance screening to alleviate some of these challenges. In proof-of-principle experiments, we established appropriate conditions for resistance

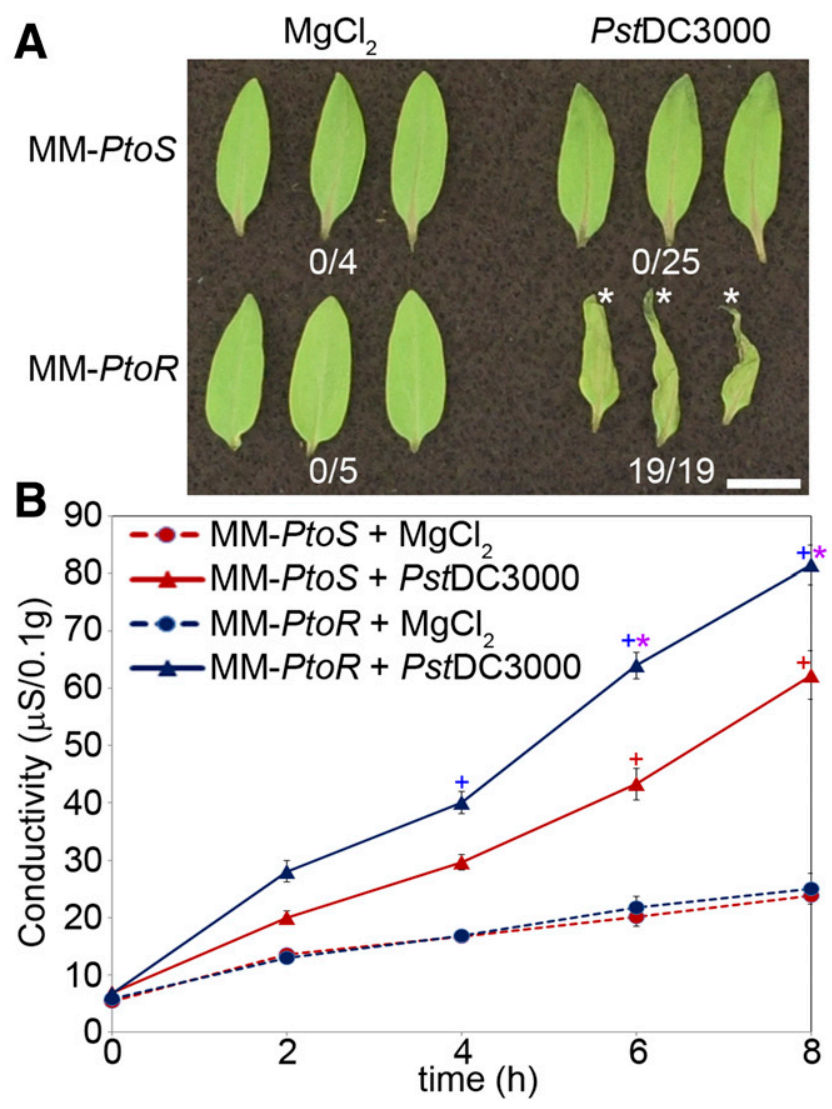

Fig. 2. Demonstration of the hypersensitive response (HR) caused by Pseudomonas syringae pv. tomato DC3000 in resistant but not susceptible tomato seedlings. A, Moneymaker-PtoS (MM-PtoS) or Moneymaker-PtoR (MM-PtoR) tomato seedlings were grown in soil for 10 days, before being vacuum infiltrated with approximately $5 \times 10^{7} \mathrm{CFU}$ per milliliter of P. syringae pv. tomato DC3000 (PstDC3000). Plants were photographed $8 \mathrm{~h}$ after infiltration. The number of leaves showing a HR is indicated under the leaves. The scale bar is $1 \mathrm{~cm}$. B, Electrolyte leakage of tomato cotyledons after vacuum infiltration with a DC3000 suspension of approximately $5 \times$ $10^{7} \mathrm{CFU} / \mathrm{ml}$. Differences between means were determined by a one-factor analysis of variance, using a general linear model procedure $(P<0.001)$ followed by multiple comparisons of means, using Tukey's posthoc test. Purple asterisks (*) indicate significant differences between MM-PtoR and MM-PtoS genotypes treated with DC3000 for a given time point. Plus signs (red +: MM-PtoS, blue +: MM-PtoR) indicate significant differences between treatments (10 $\mathrm{mM} \mathrm{MgCl}_{2}$ or DC3000) within the same genotype for a given time point. The error bars indicate the standard error. The experiment was repeated two times with similar results. 
and disease by infecting DC3000 on isogenic tomato cultivars that differ in the Pto/Prf gene cluster. RG and MM cultivars show strong resistance to DC3000 when they carry the Pto/Prf gene cluster (PtoR) and are susceptible when they lack this cluster (PtoS) (Laterrot 1993; Pedley and Martin 2003;
Rosebrock et al. 2007). We found that the level of bacterial inoculum was critical in discriminating between resistance and susceptibility in tomato seedlings. We observed strong consistent phenotypes with optimized bacterial densities (Fig. 1B) and showed that resistance was associated with lower

A RG-PtoR

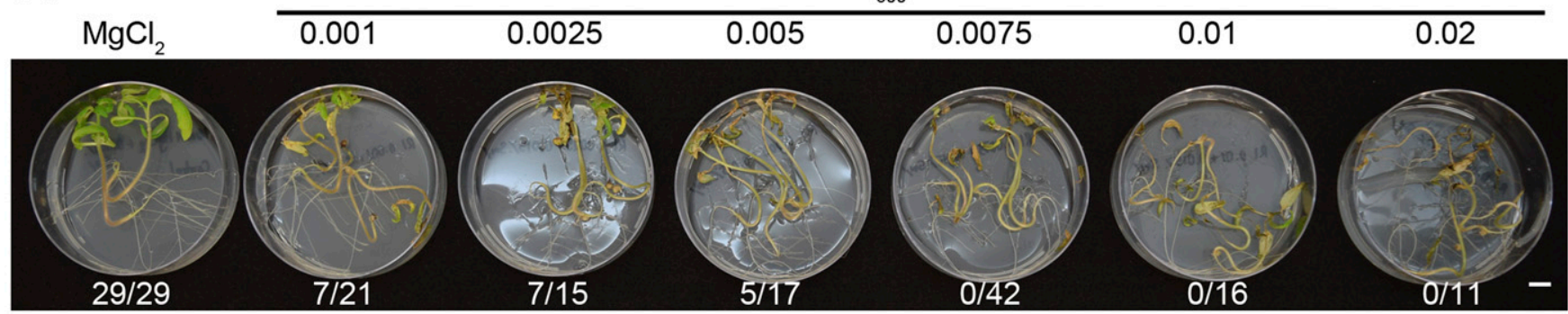

B

RGPtoR

C

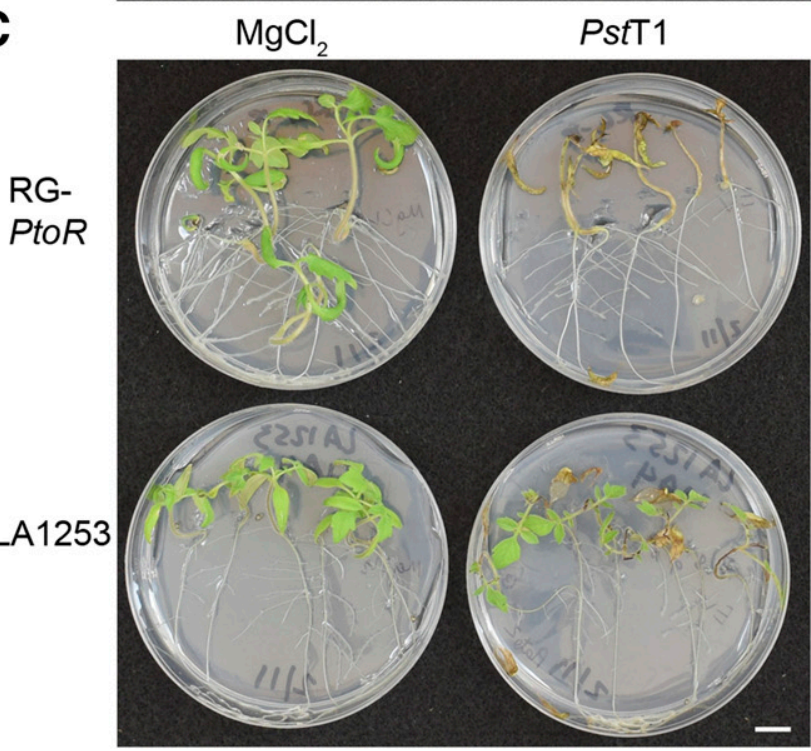

D

LA1329

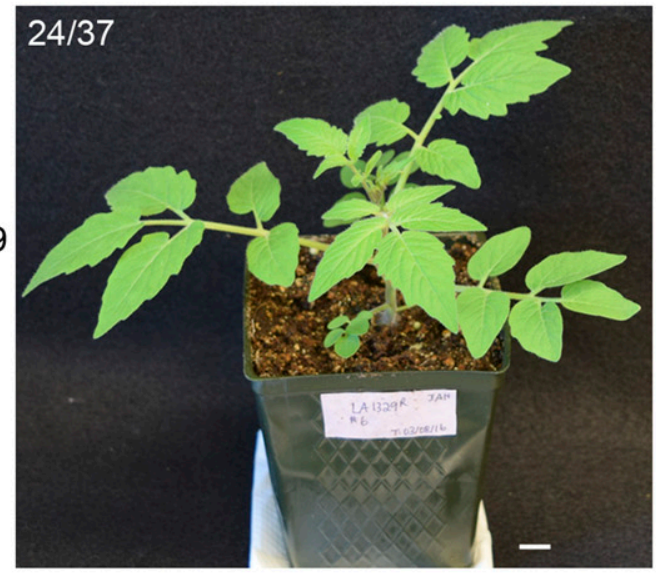

E

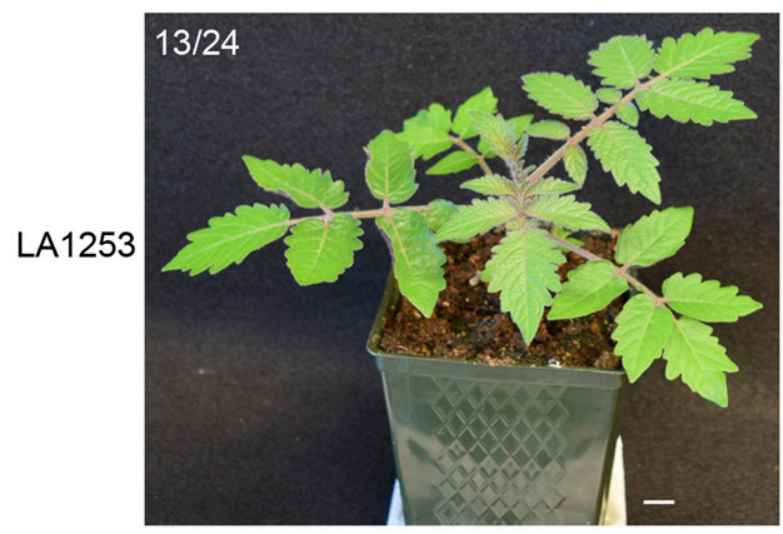

Fig. 3. Phenotypic optimization of Pseudomonas syringae pv. tomato $\mathrm{T} 1$ optical densities in susceptible tomato seedlings 10 days postinfection and identification of two wild tomato accessions that are resistant to $P$. syringae pv. tomato T1. A, Rio Grande-PtoS (RG-PtoS) tomato seedlings were grown on $0.5 \times$ Murashige and Skoog (MS) plates for 10 days, before being flooded with $10 \mathrm{mM} \mathrm{MgCl}_{2}$ containing the indicated optical densities of $P$. syringae pv. tomato T1 (Pst T1) and 0.015\% Silwet. The scale bar is $1 \mathrm{~cm}$. B and $\mathbf{C}$, Phenotypic characterization of resistance or disease symptoms 10 to 14 days postinfection. Rio Grande-PtoR (RG-PtoR) and LA1329 (B) or LA1253 (C) tomato seedlings were grown on $0.5 \times$ MS plates for 10 days, before being flooded with P. syringae pv. tomato T1. D and E, Resistant LA1329 (D) and LA1253 (E) seedlings were grown to the adult stage after flood inoculation. Adult plants did not show any symptoms of disease. For each wild accession, the number of seedlings that survived out of the total number tested is shown. The scale bar is $1 \mathrm{~cm}$. 
bacterial growth $(\log 6.5)$ than susceptibility (log 9) (Fig. 1C). We further demonstrated that resistant seedlings carrying the Pto/Prf cluster developed rapid strong macroscopic HRs (Fig. 2A) and exhibited rapid ion leakage (Fig. 2B). AvrPto and AvrPtoB are early-acting effector proteins that target PTI (Kvitko et al. 2009); thus, it is not surprising that they elicit a very rapid immune response in resistant plants. Susceptible seedlings lacking the Pto/Prf cluster lacked macroscopic HRs and displayed slower ion leakage, consistent with disease symptoms. Taken together, we conclude that the seedling resistance assay recapitulates critical measures of resistance and susceptibility that are observed in adult tomato plants.

Uppalapati and colleagues (2008) developed a tomato seedling assay to investigate the virulence function of the bacterial phytotoxin coronatine. Coronatine is a methyl-jasmonate mimic that promotes stomatal opening, which allows $P$. syringae to enter the apoplast (Melotto et al. 2006). In this assay, 4-day-old seedlings were flooded in a bacterial suspension of approximately $5 \times 10^{7} \mathrm{CFU} / \mathrm{ml}$, which was 20 -fold higher than the concentration used in our assay. However, Uppalapati and colleagues (2008) were investigating bacterial virulence, while we were screening for tomato lines with resistance to $P$. syringae. We found that high bacterial titers could overwhelm genetically encoded resistance in our assay. Thus, in establishing infectious conditions for DC3000 and T1, we selected the lowest bacterial concentration that discriminated between resistance and susceptibility (Figs. 1 and 2, DC3000) or resulted in susceptibility (Fig. 3, T1).

Interestingly, seedlings in our screen displayed more consistent and discrete phenotypes of susceptibility or resistance (Figs. 3 and 4), as compared with adult plants (Fig. 5). We found that it was not possible to bin the adult LA1329 plants into different phenotypic categories of susceptibility or resistance, since the sample sizes were much smaller than in the seedling assay and phenotypic differences in disease symptoms in the adult plants were much more nuanced (Fig. 5). The difference in phenotypes may be due, in part, to environmental factors. A Petri dish environment is likely to be more humidified, which would result in open stomata and allow the bacteria to enter more easily. In addition, the highly reduced growth needs of seedlings allowed us to screen much greater numbers of seedlings compared with adult plants. Given the genetically complex nature of wild tomato accessions, there was a clear benefit in screening enough individuals to account for incomplete penetrance, genetically complex resistance, or other confounding effects. Our seedling results suggest that the population does segregate for resistance (Fig. 4), which may complicate treating the LA1329 plants as a genetically consistent population. The high-throughput nature of the seedling assay and its strong consistent phenotypes allowed us to identify resistance phenotypes much more readily and allowed us to discriminate between susceptible and resistant seedlings within an accession (Fig. 4). Our results also suggest that the seedling assay will be very useful in mapping QTL for resistance.

Tomato accessions are also able to recognize PAMPs through PRR proteins, which are often receptor-like kinases (RLKs). The FLS2 receptor, first identified in Arabidopsis thaliana, recognizes the flg22 epitope of flagellin that is found in DC3000 and many other strains (Cai et al. 2011; Clarke et al. 2013; Zipfel et al. 2006). The recently identified FLS3 RLK from $S$. pimpinellifolium LA1589 recognizes a second flagellin epitope (flgII-28) found in T1 (Cai et al. 2011; Clarke et al. 2013; Hind et al. 2016). flgII-28 from T1 contains two amino acid polymorphisms and, compared with flgII-28 from DC3000, elicits greater reactive oxygen species production in

\begin{tabular}{lcc} 
A & MM-Ptos & LA1329 \\
\hline susceptible & 20 & 18 \\
resistant & 0 & 27 \\
total & 20 & 45 \\
\hline
\end{tabular}

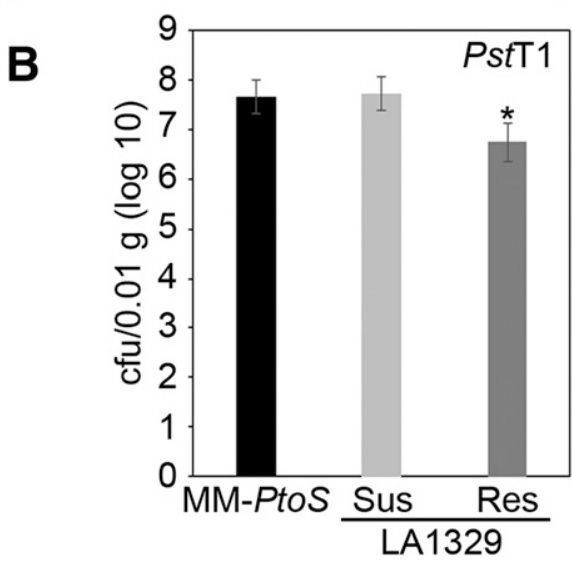

Fig. 4. LA1329 displays restricted bacterial growth compared with a susceptible line. Moneymaker-PtoS (MM-PtoS) or LA1329 tomato seedlings were grown on $0.5 \times$ Murashige and Skoog plates for 10 days, before being flooded with $P$. syringae pv. tomato T1. A, The number of LA1329 individuals that were resistant or susceptible to $P$. syringae pv. tomato T1 $(P s t \mathrm{~T} 1)$ from two combined experiments is shown in the table. B, Bacterial counts were determined 4 days postinfection on MM-PtoS $(n=10)$ and LA1329 $(n=26)$ seedlings and were normalized to $0.01 \mathrm{~g}$ of tissue. For LA1329, the counts are separated according to the two observed phenotypic groups, susceptible (Sus) or resistant (Res). The asterisk above the bar indicates statistical difference as determined by a one-factor analysis of variance, using a general linear model procedure $(P<0.001)$ followed by a multiple comparisons of means, using Tukey's post hoc test. The error bars indicate the standard deviation. One representative experiment is shown. The experiment was repeated two times with similar results.

Table 2. Candidate wild tomato accessions with resistance to Pseudomonas syringae pv. tomato T1

\begin{tabular}{lllc}
\hline Wild accession & \multicolumn{1}{c}{ Species } & Geographic location & Seedling survival $^{\mathbf{y}}$ \\
\hline LA1253 & S. habrochaites & Ecuador, Peru & $28 / 41(68 \%)$ \\
LA1329 & S. neorickii & Apurimac, Peru & $24 / 38(63 \%)$ \\
LA4023 & S. neorickii & Azuay, Ecuador & $19 / 54(35 \%)$ \\
LA1689 & S. pimpinellifolium & Piura, Peru & $10 / 32(31 \%)$ \\
LA1578 & S. pimpinellifolium & La Libertad, Peru & $9 / 37(24 \%)$ \\
LA0373 & S. pimpinellifolium & Ancash, Peru & $10 / 43(23 \%)$ \\
LA1590 & S. pimpinellifolium & La Libertad, Peru & $17 / 81(21 \%)^{\mathrm{z}}$ \\
LA1547 & S. pimpinellifolium & Carachi, Ecuador & $9 / 68(13 \%)^{\mathrm{z}}$ \\
LA1237 & S. pimpinellifolium & Esmaraldas, Ecuador & Medium \\
LA2401 & S. pimpinellifolium & Ancash, Peru & Weak \\
\hline
\end{tabular}

${ }^{y}$ Average frequency of seedling survival was calculated from the progeny of several resistant individuals.

${ }^{\mathrm{z}}$ Number of resistant seedlings from total seedlings tested. 
FLS3 tomato than flg22 (Clarke et al. 2013; Zipfel et al. 2004). The FLS3 receptor is specific to the Solanaceae family and belongs to a different subclade than the tomato homologs of FLS2, the elongation-factor Tu receptor EFR, and the Xanthomonas oryzae Xa21 receptor (Andolfo et al. 2013; Cai et al. 2011; Clarke et al. 2013; Hind et al. 2016; Park and Ronald 2012; Zipfel et al. 2006). As FLS3 segregates as a monogenic dominant gene, the resistance we observed in LA1329 (Table 2; Figs. 3B and 4) is unlikely to be due to FLS3. We also think it is unlikely that LA1329 carries a canonical $R$ gene, as we did not observe a HR in response to T1 in LA1329 seedlings (data not shown) and most $R$ genes are monogenic and dominant or semidominant (Dangl et al. 2013).

In a screen for T1 resistance in $S$. habrochaites lines, Bao and colleagues (2015) found resistance in adult plants of LA2109 and additional $S$. habrochaites lines located in the same geographic region. This work independently identified LA1253 (Bao et al. 2015) as being resistant to T1 (Fig. 3C). In LA2109, resistance segregated as a complex genetic trait, with $24 \%$ of the variability attributed to qRph1 and $26 \%$ of the variability attributed to qRph2 (Bao et al. 2015). We found that resistance in LA1253 also appears to be a complex genetic trait, with 60 to $68 \%$ of seedlings showing resistance (Table 2). qRph1 was mapped to a 139-gene interval containing both receptor-like proteins and RLKs (Bao et al. 2015). It is not clear whether LA2109 carries the same genes involved in resistance as LA1253. Although resistance can be developmentally regulated (Develey-Rivière and Galiana 2007; Whalen 2005), this result demonstrates that the seedling resistance assay can effectively identify the same lines as more traditional adult screens.

T1 is closely related to $P$. syringae pv. tomato race 1 strains A9 and 407, which have been used in genetic screens for resistance (Cai et al. 2011; Kunkeaw et al. 2010; Thapa et al. 2015). A recent screen identified resistance in $S$. peruvianum LA3799, S. peruvianum var. dentatum PI128655, S. chilense LA2765, S. habrochaites LA2869, and S. habrochaites LA1777 (Thapa et al. 2015). Using introgression lines between LA1777 and S. lycopersicum E6203, Thapa and colleagues (2015) identified four QTL that contribute to resistance in LA1777. Mapping the genes responsible for resistance was complicated by the small contributions of each QTL in the introgression lines. Our seedling resistance assay could expedite a QTL mapping screen by allowing for greater throughput and more stringent phenotypes.

In summary, we established a rigorous high-throughput tomato seedling resistance assay that demonstrates critical measures of susceptibility and resistance toward $P$. syringae. This assay is very useful in screening large numbers of lines and seedlings, with highly reduced needs for growth space and growth time. Using this assay, we identified two wild tomato accessions that display resistance toward $\mathrm{T} 1$ in both seedlings and adult plants. This work will help develop new genetic tools to protect tomato from emerging $P$. syringae race 1 strains.

\section{MATERIALS AND METHODS}

Plant materials and growth conditions.

Seeds were sterilized in a $50 \%$ bleach solution for $30 \mathrm{~min}$ and were washed five times with sterile nanopure $\mathrm{H}_{2} \mathrm{O}$ before plating or sowing out. Sterilized seeds were stratified at $4^{\circ} \mathrm{C}$ on soil or plates for at least 3 days, to synchronize germination. Seeds were evenly spaced on $100 \times 25 \mathrm{~mm}$ plates containing $0.5 \times$ MS (Caisson Laboratories, Inc.) and $0.8 \%$ agar media. We aimed to have five germinated seedlings per plate; however, the susceptible control always died, regardless of the number of germinated seedlings. Tomato plants or plates oriented vertically were grown under $16 \mathrm{~h}$ of light (approximately 220 microeinsteins per square meter per second) and $8 \mathrm{~h}$ of darkness at $22^{\circ} \mathrm{C}$. Adult plants were grown for four to five weeks in Sunshine Mix \#1/LC1 (Sun Gro Horticulture Canada Ltd.) supplemented with 15:9:12 fertilizer. The following tomato accessions were used: RG-PtoR, RG-PtoS, MM-PtoR, MM$P t o S$, and wild accessions obtained from the Tomato Genetics Resource Center. MM-PtoR is a near-isogenic MM line that carries the Pto/Prf cluster and is also called Movione (TGRC LA3472) (Laterrot 1993). We typically tested 10 seedlings from each of the 96 wild accessions in the primary screen.

\section{Bacterial strains and routine culture conditions.}

DC3000 and T1 were grown in King's broth (KB). Antibiotics were used at the following concentrations: $50 \mu \mathrm{g} / \mathrm{ml} \mathrm{ri-}$ fampicin, $50 \mu \mathrm{g} / \mathrm{ml}$ cycloheximide.

\section{$P$. syringae seedling infection assays.}

For HR and ion leakage assays, $P$. syringae was resuspended to an optical density at $600 \mathrm{~nm}\left(\mathrm{OD}_{600}\right)$ of 0.1 (approximately $5 \times 10^{7} \mathrm{CFU} / \mathrm{ml}$ ) with $0.004 \%$ Silwet L-77 and was vacuum infiltrated into 10-day-old tomato seedlings for $2 \mathrm{~min}$. The HR was scored at 8 to $10 \mathrm{~h}$. For ion leakage assays, cotyledons were removed, blotted, weighed, and floated on nanopure $\mathrm{H}_{2} \mathrm{O}$ for $30 \mathrm{~min}$. Cotyledons were transferred to $6 \mathrm{ml}$ of nanopure $\mathrm{H}_{2} \mathrm{O}$, and readings were taken with an Orion 3 Star conductivity meter (Thermo Electron Corp.). The cotyledon masses were normalized to $0.1 \mathrm{~g}$. For the seedling flood assay and seedling

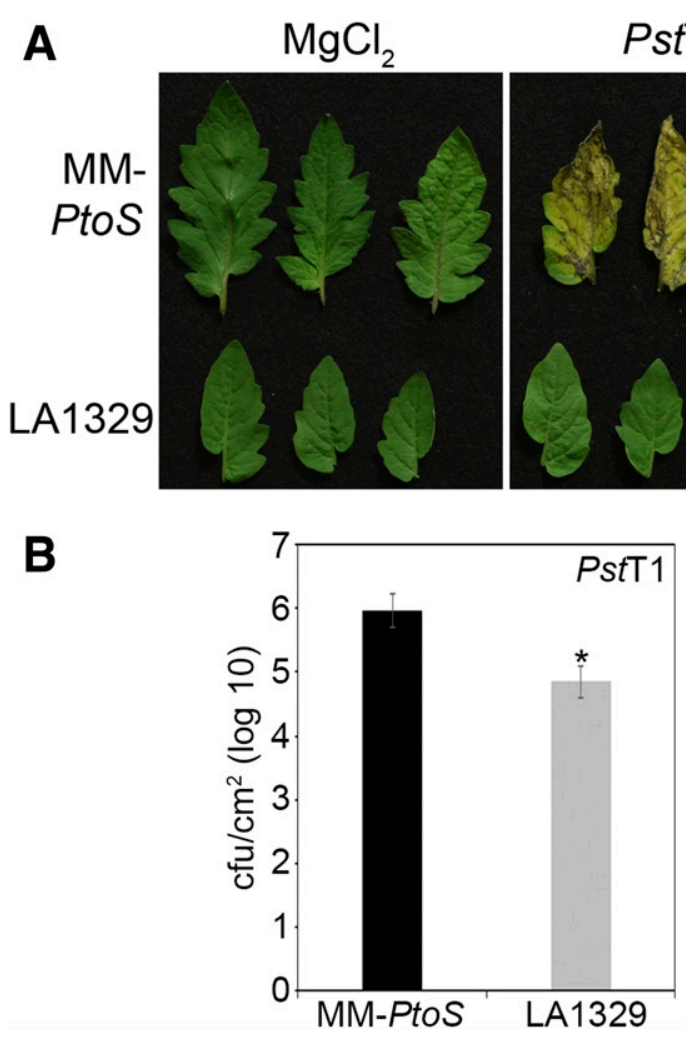

Fig. 5. Resistance to Pseudomonas syringae pv. tomato $\mathrm{T} 1$ is observed in adult LA1329 plants. LA1329 or Moneymaker-PtoS (MM-PtoS) were grown to the four to six leaf stage and were dip-inoculated with a bacterial suspension at an optical density of 0.2. A, Leaves were photographed 6 days after infection. The scale bar indicates $1 \mathrm{~cm}$. B, Bacterial counts were determined 5 days postinfection on LA1329 $(n=9)$ and MM-PtoS $(n=5)$ plants. The asterisk above the bar indicates statistical difference determined by a one-factor analysis of variance, using a general linear model procedure $(P<0.001)$ followed by a multiple comparisons of means, using Tukey's post hoc test. The error bars indicate the standard deviation. The experiment was repeated three times with similar results. 
growth assays, $P$. syringae was diluted to an $\mathrm{OD}_{600}$ of 0.005 (DC3000) or 0.0075 (T1) with $0.015 \%$ Silwet L-77. Ten-dayold seedlings were flooded for 3 min with $6 \mathrm{ml}$ of inoculum or $10 \mathrm{mM} \mathrm{MgCl} 2$ and were incubated for 10 days. Seedlings were scored for disease or resistance at least 7 (DC3000) or 10 (T1) days after flooding. For growth assays on seedlings or cotyledons, tissue was surface-sterilized in $70 \%$ ethanol for $10 \mathrm{~s}$ and was rinsed in nanopure $\mathrm{H}_{2} \mathrm{O}$ for $10 \mathrm{~s}$. Seedlings or cotyledons were individually weighed, were homogenized in $10 \mathrm{mM} \mathrm{MgCl}_{2}$, and were plated on $\mathrm{KB}$ with rifampicin and cycloheximide on day 4 for colony counting. Cycloheximide is used to prevent fungal contamination. Since seedlings or cotyledons were too small to core, the colony counts were normalized to $0.1 \mathrm{~g}$ of tissue for seedlings, because this was the average mass of the seedlings (Table 1), or to $0.01 \mathrm{~g}$ of tissue for the cotyledons, because this was the average mass of one MM-PtoS cotyledon (data not shown).

\section{$P$. syringae adult infection assays.}

Adult tomato plants grown to the four- to six-leaf stage were submerged and swirled in $\mathrm{T} 1$ inoculum at an $\mathrm{OD}_{600}$ of 0.2 with $0.02 \%$ Silwet L-77. Plants were placed under a high humidity dome and were phenotyped after 6 to 10 days. For in planta growth assays, four disks (total of $1 \mathrm{~cm}^{2}$ ) were harvested, were ground in $10 \mathrm{mM} \mathrm{MgCl}$, and were plated on $\mathrm{KB}$ with rifampicin and cycloheximide on day 5, to count colonies.

\section{Statistical analyses.}

The data were analyzed using a one-factor analysis of variance, using a general linear model procedure followed by a multiple comparisons of means, using Tukey's post hoc test. A significance level of $\alpha=0.05$ was chosen for all statistical analyses. Data were statistically analyzed using Minitab 17 software (Minitab Inc.).

\section{ACKNOWLEDGMENTS}

We are grateful to A. Liu and C. Lan for assistance with the screening of wild tomato accessions and $\mathrm{C}$. Ye for assistance with growing plants. We thank G. Coaker for the kind gift of the T1 strain and the Tomato Genetics Resource Center for seed stocks. We thank Plant Gene Expression Center greenhouse staff L. Poasa and J. Calfas for assistance with tomato plants. We thank K. Schreiber and M. Baudin for constructive feedback on the manuscript. Research on plant immunity in the Lewis laboratory was supported by United States Department of Agriculture Agricultural Research Service 5335-21000-040-00D (J. D. Lewis).

\section{LITERATURE CITED}

Almeida, N. F., Yan, S., Lindeberg, M., Studholme, D. J., Schneider, D. J., Condon, B., Liu, H., Viana, C. J., Warren, A., Evans, C., Kemen, E., Maclean, D., Angot, A., Martin, G. B., Jones, J. D., Collmer, A., Setubal, J. C., and Vinatzer, B. A. 2009. A draft genome sequence of Pseudomonas syringae pv. tomato T1 reveals a type III effector repertoire significantly divergent from that of Pseudomonas syringae pv. tomato DC3000. Mol. Plant-Microbe Interact 22:52-62.

Andolfo, G., Sanseverino, W., Rombauts, S., Van de Peer, Y., Bradeen, J. M., Carputo, D., Frusciante, L., and Ercolano, M. R. 2013. Overview of tomato (Solanum lycopersicum) candidate pathogen recognition genes reveals important Solanum $R$ locus dynamics. New Phytol. 197: 223-237.

Arredondo, C. R., and Davis, R. M. 2000. First report of Pseudomonas syringae pv. tomato race 1 on tomato in California. Plant Dis. 84:371.

Bao, Z. L., Meng, F. H., Strickler, S. R., Dunham, D. M., Munkvold, K. R., and Martin, G. B. 2015. Identification of a candidate gene in Solanum habrochaites for resistance to a race 1 strain of Pseudomonas syringae pv. tomato. Plant Genome 8.

Buonaurio, R., Stravato, V. M., and Capelli, C. 1996. Occurrence of Pseudomonas syringae pv. tomato race 1 in Italy on Pto gene-bearing tomato plants. J. Phytopathol. 144:437-440.
Cai, R., Lewis, J., Yan, S., Liu, H., Clarke, C. R., Campanile, F., Almeida N. F., Studholme, D. J., Lindeberg, M., Schneider, D., Zaccardelli, M., Setubal, J. C., Morales-Lizcano, N. P., Bernal, A., Coaker, G., Baker, C. Bender, C. L., Leman, S., and Vinatzer, B. A. 2011. The plant pathogen Pseudomonas syringae pv. tomato is genetically monomorphic and under strong selection to evade tomato immunity. PLoS Pathog. 7:e1002130.

Clarke, C. R., Chinchilla, D., Hind, S. R., Taguchi, F., Miki, R., Ichinose, Y., Martin, G. B., Leman, S., Felix, G., and Vinatzer, B. A. 2013. Allelic variation in two distinct Pseudomonas syringae flagellin epitopes modulates the strength of plant immune responses but not bacterial motility. New Phytol. 200:847-860.

Dangl, J. L., Horvath, D. M., and Staskawicz, B. J. 2013. Pivoting the plant immune system from dissection to deployment. Science 341:746-751.

Dangl, J. L., and Jones, J. D. G. 2001. Plant pathogens and integrated defence responses to infection. Nature 411:826-833.

Develey-Rivière, M.-P., and Galiana, E. 2007. Resistance to pathogens and host developmental stage: A multifaceted relationship within the plant kingdom. New Phytol. 175:405-416.

Galán, J. E., and Wolf-Watz, H. 2006. Protein delivery into eukaryotic cells by type III secretion machines. Nature 444:567-573.

Heath, M. C. 2000. Hypersensitive response-related death. Plant Mol. Biol. 44:321-334.

Hind, S. R., Strickler, S. R., Boyle, P. C., Dunham, D. M., Bao, Z., O’Doherty, I. M., Baccile, J. A., Hoki, J. S., Viox, E. G., Clarke, C. R., Vinatzer, B. A., Schroeder, F. C., and Martin, G. B. 2016. Tomato receptor FLAGELLIN-SENSING 3 binds flgII-28 and activates the plant immune system. Nat Plants 2:16128.

Jones, J. D. G., and Dangl, J. L. 2006. The plant immune system. Nature 444:323-329.

Katagiri, F., Thilmony, R., and He, S. Y. 2002. The Arabidopsis thalianaPseudomonas syringae interaction. Pages 1-35 in: The Arabidopsis Book. C. R. Somerville and E. M. Meyerowitz, eds. American Society of Plant Biologists, Rockville, MD, U.S.A.

Kim, Y. J., Lin, N. C., and Martin, G. B. 2002. Two distinct Pseudomonas effector proteins interact with the Pto kinase and activate plant immunity. Cell 109:589-598.

Kunkeaw, S., Tan, S., and Coaker, G. 2010. Molecular and evolutionary analyses of Pseudomonas syringae pv. tomato race 1. Mol. PlantMicrobe Interact 23:415-424.

Kvitko, B. H., Park, D. H., Velásquez, A. C., Wei, C. F., Russell, A. B., Martin, G. B., Schneider, D. J., and Collmer, A. 2009. Deletions in the repertoire of Pseudomonas syringae pv. tomato DC3000 type III secretion effector genes reveal functional overlap among effectors. PLoS Pathog. 5:e1000388.

Laterrot, H. 1993. Revised list of near isogenic tomato lines in Moneymaker type with different genes for disease resistances. Report of the Tomato Genetics Cooperative 43:79-80.

Lawton, M. B., and MacNeill, B. H. 1986. Occurrence of race 1 of Pseudomonas syringae pv. tomato on field tomato in southwestern Ontario. Can. J. Plant Pathol. 8:85-88.

Lin, N. C., Abramovitch, R. B., Kim, Y. J., and Martin, G. B. 2006. Diverse AvrPtoB homologs from several Pseudomonas syringae pathovars elicit Pto-dependent resistance and have similar virulence activities. Appl. Environ. Microbiol. 72:702-712.

Lin, N. C., and Martin, G. B. 2005. An avrPtolavrPtoB mutant of Pseudomonas syringae pv. tomato DC3000 does not elicit Pto-mediated resistance and is less virulent on tomato. Mol. Plant-Microbe Interact 18:43-51.

Lin, N. C., and Martin, G. B. 2007. Pto- and Prf-mediated recognition of AvrPto and AvrPtoB restricts the ability of diverse Pseudomonas syringae pathovars to infect tomato. Mol. Plant-Microbe Interact 20:806-815.

Martin, G. B., Brommonschenkel, S. H., Chunwongse, J., Frary, A., Ganal, M. W., Spivey, R., Wu, T., Earle, E. D., and Tanksley, S. D. 1993. Mapbased cloning of a protein kinase gene conferring disease resistance in tomato. Science 262:1432-1436.

Melotto, M., Underwood, W., Koczan, J., Nomura, K., and He, S. Y. 2006. Plant stomata function in innate immunity against bacterial invasion. Cell 126:969-980.

Milijasevic, S., Todorovic, B., Rekanovic, E., Potocnik, I., and Gavrilovic, V. 2009. Races and hosts of Pseudomonas syringae pv. tomato in Serbia. Arch. Biol. Sci. 61:93-103.

Mott, G. A., Middleton, M. A., Desveaux, D., and Guttman, D. S. 2014 Peptides and small molecules of the plant-pathogen apoplastic arena. Front. Plant Sci. 5:677.

Park, C. J., and Ronald, P. C. 2012. Cleavage and nuclear localization of the rice XA21 immune receptor. Nat. Commun. 3:920.

Pedley, K. F., and Martin, G. B. 2003. Molecular basis of Pto-mediated resistance to bacterial speck disease in tomato. Annu. Rev. Phytopathol 41:215-243. 
Pitblado, R. E., and MacNeill, B. H. 1983. Genetic basis of resistance to Pseudomonas syringae pv. tomato in field tomatoes. Can. J. Plant Pathol. 5:251-255.

Ronald, P. C., Salmeron, J. M., Carland, F. M., and Staskawicz, B. J. 1992. The cloned avirulence gene avrPto induces disease resistance in tomato cultivars containing the Pto resistance gene. J. Bacteriol. 174:1604-1611.

Rose, L. E., Langley, C. H., Bernal, A. J., and Michelmore, R. W. 2005. Natural variation in the Pto pathogen resistance gene within species of wild tomato (Lycopersicon). I. Functional analysis of Pto alleles. Genetics 171:345-357.

Rosebrock, T. R., Zeng, L., Brady, J. J., Abramovitch, R. B., Xiao, F., and Martin, G. B. 2007. A bacterial E3 ubiquitin ligase targets a host protein kinase to disrupt plant immunity. Nature 448:370-374

Salmeron, J. M., Barker, S. J., Carland, F. M., Mehta, A. Y., and Staskawicz, B. J. 1994. Tomato mutants altered in bacterial disease resistance provide evidence for a new locus controlling pathogen recognition. Plant Cell 6:511-520.

Salmeron, J. M., Oldroyd, G. E. D., Rommens, C. M. T., Scofield, S. R., Kim, H. S., Lavelle, D. T., Dahlbeck, D., and Staskawicz, B. J. 1996. Tomato Prf is a member of the leucine-rich repeat class of plant disease resistance genes and lies embedded within the Pto kinase gene cluster. Cell 86:123-133.

Schneider, R. W., and Grogan, R. G. 1977. Bacterial speck of tomato: Sources of inoculum and establishment of a resident population. Phytopathology 67:388-394.

Scofield, S. R., Tobias, C. M., Rathjen, J. P., Chang, J. H., Lavelle, D. T., Michelmore, R. W., and Staskawicz, B. J. 1996. Molecular basis of gene-forgene specificity in bacterial speck disease of tomato. Science 274:2063-2065.
Segonzac, C., and Zipfel, C. 2011. Activation of plant pattern-recognition receptors by bacteria. Curr. Opin. Microbiol. 14:54-61.

Thapa, S. P., Miyao, E. M., Michael Davis, R., and Coaker, G. 2015. Identification of QTLs controlling resistance to Pseudomonas syringae pv. tomato race 1 strains from the wild tomato, Solanum habrochaites LA1777. Theor. Appl. Genet. 128:681-692.

Underwood, W., Melotto, M., and He, S. Y. 2007. Role of plant stomata in bacterial invasion. Cell. Microbiol. 9:1621-1629.

Uppalapati, S. R., Ishiga, Y., Wangdi, T., Urbanczyk-Wochniak, E., Ishiga, T., Mysore, K. S., and Bender, C. L. 2008. Pathogenicity of Pseudomonas syringae pv. tomato on tomato seedlings: Phenotypic and gene expression analyses of the virulence function of coronatine. Mol. Plant-Microbe Interact 21:383-395.

Whalen, M. C. 2005. Host defence in a developmental context. Mol. Plant Pathol. 6:347-360.

Zipfel, C., Kunze, G., Chinchilla, D., Caniard, A., Jones, J. D. G., Boller, T., and Felix, G. 2006. Perception of the bacterial PAMP EF-Tu by the receptor EFR restricts Agrobacterium-mediated transformation. Cell 125:749-760.

Zipfel, C., Robatzek, S., Navarro, L., Oakeley, E. J., Jones, J. D. G., Felix, G., and Boller, T. 2004. Bacterial disease resistance in Arabidopsis through flagellin perception. Nature 428:764-767.

\section{AUTHOR-RECOMMENDED INTERNET RESOURCE}

Tomato Genetics Resource Center website: tgrc.ucdavis.edu 